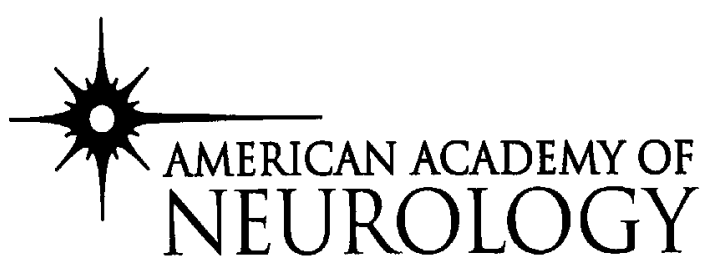

\title{
PRACTICE ADVISORY: THE USE OF FELBAMATE IN THE TREATMENT OF PATIENTS WITH INTRACTABLE EPILEPSY
}

\author{
Report of the Quality Standards Subcommittee of the American Academy of Neurology \\ and the American Epilepsy Society
}

\author{
J. French, MD; M. Smith, MD; E. Faught, MD; and L. Brown, MD
}

\begin{abstract}
Background/justification. Epilepsy is a common condition, affecting up to $1 \%$ of the population. Until recently, there were only a handful of effective medications to treat this condition, many of which produced unwanted side effects or were capable of producing serious adverse events in some people. Despite these drawbacks, from 1978, when valproate was introduced, until 1993, no new therapies emerged. In 1993, felbamate was approved by the Food and Drug Administration (FDA). At that time, it represented a significant advance for many patients with inadequately controlled seizures or with significant side effects for whom no options had been available. The substantial need for a new agent was evidenced by the fact that within 1 year, felbamate had been prescribed for 126,000 patients with epilepsy. ${ }^{1}$ Many of these patients experienced complete seizure control for the first time. Others found that felbamate, which does not have the central nervous system depressant effect of many other agents, provided significant improvements in quality of life.

In September 1994 the FDA issued a "dear doctor" letter, warning of a higher than expected incidence of aplastic anemia and hepatic failure among patients receiving felbamate. ${ }^{2}$ In all, 33 US cases of aplastic anemia occurred between January and October of 1994. Eighteen patients experienced hepatic failure. ${ }^{3}$ This prompted most physicians to remove most or all of their patients from felbamate therapy. Of the original cohort, only 12,000 remained on felbamate. A similar number have continued to the present.

Of interest, no new cases of aplastic anemia have been reported in patients who remained on felbamate, or among the smaller cohort who have initiated therapy since that time. Some have argued that the initial high incidence of serious adverse events may have overestimated the magnitude of the problem, as many of the affected patients had other confounding factors and the incidence estimates were based on many unconfirmed assumptions. Other believe that patients on long-term therapy may have diminishing risk of serious adverse events as time passes.

-Because the potential risks are not well delineated, physicians who may choose to use felbamate are in a difficult position, as they must decide the risk/benefit ratio for an individual patient.
\end{abstract}

Purpose. The purpose of this advisory is to:

1. Determine the current role of felbamate for treatment of various types of epilepsy;

2. Provide guidelines to ensure maximum safety and effectiveness when the risk/benefit ratio is in favor of the use of felbamate.

Process. A Medline search was performed for articles including the key word "felbamate." The search was restricted to English language only and human studies. The search identified 105 articles. The working group reviewed abstracts of all articles.

Of the 105 articles, 54 were identified as relevant to the topics of efficacy, practice, treatment guidelines, and side effects. All clinical studies were reviewed in entirety, including case reports. Articles were excluded if they reviewed multiple drugs, discussed only mechanism of action, consisted of news reports, or summarized previous data without providing new insight or opinion.

From the American Academy of Neurology, St. Paul, MN. Approved by the AAN Quality Standards Subcommittee October 17, 1998. Approved by the Practice Committee January 23, 1999. Approved by the Executive Board of the AAN February 27, 1999. Received December 29, 1998. Accepted in final form February 27, 1999.

Address correspondence and reprint requests to QSS, American Academy of Neurology, 1080 Montreal Ave., St Paul, MN 55116.

Copyright (C) 1999 by the American Academy of Neurology 
Articles were rated as Class I, II, or III (see Appendix 1 for definitions).

The 54 articles reviewed could be classified as follows:

Class I: Nine articles, seven related to efficacy and toxicity and two to pharmacokinetics.

Class II: One article related to brain levels of felbamate.

Class III: Forty-four articles including case reports, historic control studies, and reviews with expert opinion.

In addition to the information obtained through the literature search, each panel member reviewed his or her assigned articles' reference lists to determine whether any important articles were missed. Unpublished data on safety issues were also obtained from Carter Wallace Pharmaceuticals (Cranbury, NJ).

Studies were assessed for study design, toxicity (dose-dependent and idiosyncratic), and efficacy, including patient characteristics, seizure type being treated, and duration of treatment. Reviews were assessed to determine expert opinion on efficacy, toxicity, and the place of felbamate in the treatment of various seizure types.

Selection of the work group. Individuals were selected to cover a broad range of expertise in epilepsy, including two individuals who participated in clinical trials of felbamate and a pediatric epilepsy specialist. All members of the working group have expertise and experience in dealing with intractable epilepsy patients.

To assess relative risk/benefit ratio of felbamate in comparison to other therapies, both medical and surgical, we reviewed relevant literature on prognosis, risks of epilepsy, risks of other antiepileptic drugs (AEDs), and surgical treatment.

Scientific evidence. Class I. There were two randomized controlled trials of felbamate as adjunctive therapy for intractable partial-onset seizures. Theodore et al. ${ }^{4}$ performed a crossover study in which felbamate was added to carbamazepine. No statistically significant difference between periods on placebo and periods on felbamate was found. However, this was attributed to the fact that carbamazepine levels were lowered by felbamate, possibly masking felbamate's antiseizure effect. Leppik et al. ${ }^{5}$ performed a crossover study in which all patients were taking carbamazepine and phenytoin as background AEDs. At a mean dose of $2300 \mathrm{mg} / \mathrm{day}$, a modest but statistically significant reduction in seizures was achieved with felbamate. The confounding effect of lowered carbamazepine and phenytoin levels in felbamate-treated patients was again noted.

The approval of felbamate in patients with partial seizures was largely due to two trials performed with novel monotherapy designs. A trial in patients undergoing presurgical evaluation of partial seizures was an intermediate situation between adjunctive and monotherapy. ${ }^{6}$ Patients had their background AEDs reduced to a variable degree for the purpose of inpatient video-EEG monitoring as part of a presurgical evaluation. Once the necessary data had been obtained, patients were randomized to felbamate or placebo in addition to their standard AEDs at reduced levels. Patients on felbamate were statistically more likely to be able to reach the 29th day of the study without experiencing four or more seizures. This trial was subsequently repeated with a requirement that all AEDs be withdrawn before randomization. ${ }^{7}$ The second monotherapy trial was performed in outpatients. ${ }^{8,9}$ Patients were randomized to felbamate $3,600 \mathrm{mg} /$ day or valproate $15 \mathrm{mg} / \mathrm{kg} / \mathrm{day}$. Subsequently, background AEDs were withdrawn. Patients randomized to felbamate were statistically more likely to reach the 112th day without reaching predetermined exit criteria, which were designed to assess significant clinical worsening.

Felbamate was also shown to be effective in Lennox-Gastaut syndrome in adults and children, and was particularly successful for tonic and atonic seizures ("drop attacks"). ${ }^{10}$ Seventy-three patients with at least 90 tonic seizures per month at baseline received felbamate or placebo as adjunctive therapy. The patients treated with felbamate had a $34 \%$ decrease in the frequency of atonic seizures, as compared with a $9 \%$ decrease in placebotreated patients. Three patients were free of all tonic seizures during the treatment phase of the trial. To date, only two other AEDs, lamotrigine and topiramate, has been demonstrated to be effective in this syndrome in the context of a placebo-controlled trial. ${ }^{11}$

Felbamate is noted to be nonsedating. Side effects are much more common in adjunctive therapy conditions than when felbamate is used as monotherapy. In randomized controlled trials, common dose-limiting side effects included nausea, abdominal distress, anorexia, insomnia, fatigue, dizziness, ataxia, and cognitive impairment. Weight loss was associated with felbamate use.

Felbamate produces drug interactions that may complicate therapy. Addition of felbamate will produce an increase in phenytoin and valproate levels. Carbamazepine levels will be reduced, but levels of carbamazepine 
epoxide, a metabolite, will increase, potentially causing toxicity. Enzyme-inducing AEDs will reduce felbamate levels, whereas coadministration of valproate will raise felbamate levels. ${ }^{1}$

Class III. There are several smaller, uncontrolled series ranging from 6 to 21 patients that suggest felbamate's efficacy in juvenile myoclonic epilepsy, ${ }^{12}$ atypical absence, ${ }^{13}$ typical absence, ${ }^{14}$ and other primary generalized seizures. ${ }^{15,16}$ An open trial in 30 children with partial epilepsy was also promising. ${ }^{17}$

The most troubling adverse events with felbamate are serious idiosyncratic events. These include serious rash, aplastic anemia, and hepatic failure. Of these, only rash was seen during randomized placebo-controlled trials. Stevens-Johnson syndrome and toxic epidermal necrolysis have been reported. ${ }^{18}$ The incidence of serious rash has not been well established, and it is not known whether this rash will occur after discontinuation and rechallenge. Thirty-three cases of aplastic anemia were reported in felbamate postmarketing surveillance. The mean number of days on felbamate at time of presentation was 154, with a range of 22 to 339 days. No cases were reported in children under the age of $13 .{ }^{19}$ The specific risk in this age group cannot be determined, as it is not known how many have received felbamate. Prior blood dyscrasias were reported in $45 \%$ of the affected patients, and $32 \%$ had a history of pre-existing immune disorder. Although these conditions could represent risk factors for developing felbamate-associated aplastic anemia, patients with these disorders might have developed aplastic anemia in the absence of felbamate therapy. These cases were therefore thought to have an unclear association with felbamate. Thirty-one reported cases of aplastic anemia were analyzed by Kaufman et al. ${ }^{20}$ They believed that 23 cases were confirmable. The others were questionable because the patients had other serious illnesses that could have caused the hematologic disturbance or had incomplete documentation. Sixty-five percent of the confirmed cases were female. The median age was 40 years. Seven patients died. All but three cases were associated with other potential possible or probable confounding factors, in most cases consisting of concurrent therapy with other AEDs, with felbamate representing only "one of several possible attributable agents" (p.1267). The authors calculate a best case estimate of 27 cases per million, and a worst case estimate of 209 cases per million. The risk in the general population is approximately 2 cases per million. The exact magnitude of risk is impossible to determine. No patients have developed aplastic anemia since the "dear doctor" letter was issued in 1994, despite 10,000 to 12,000 continued users of felbamate. If the risk was truly $1 / 3,000$ to 5,000 cases/year and the risk did not decrease over time, one would have expected several more cases to have developed. This may mean that the risk lessens over time.

Acute hepatic failure has been reported in 18 patients in the United States. Of these, there are confounding factors in nine patients. Six cases were felt to be due to status epilepticus, and one each to acetaminophen overdose, infectious hepatitis, septicemia, and diffuse intravascular coagulation. For several other cases, there is insufficient information to determine causality. Seven cases to date have been deemed "probably associated with felbamate." Five were fatal. The estimated incidence of death due to felbamate-associated hepatic failure is 1 in 26,000 to 34,000 exposures. ${ }^{19}$ Again, patients who have continued long-term therapy appear to have lower risk.

Risk of alternative therapy. When assessing the risk of a therapeutic intervention, the risks of alternative therapies, or of the decision not to make a therapeutic intervention, must also be assessed.

Uncontrolled seizures carry a risk of morbidity and mortality from accidental injury, burns, drowning, traffic accidents, and sudden death. ${ }^{21,22}$ Patients experiencing frequent seizures are also at risk for psychosocial deterioration including inability to work, drive, or maintain important family relationships. Studies have demonstrated a reduced health-related quality of life in patients with epilepsy. ${ }^{23}$ Patients with Lennox-Gastaut syndrome typically have a very high seizure frequency, and seizures are often associated with sudden falls, causing injury and emergency room visits. These patients' independence may be jeopardized by caretakers' fear that seizures will occur during independent ambulation or performance of other activities. Status epilepticus is common. $^{24}$

In addition to direct seizure risk, morbidity in epilepsy patients may derive from side effects associated with AED therapy. To date, only three AEDs - felbamate, lamotrigine, and topiramate - have proved effective in reducing seizure frequency in patients with Lennox-Gastaut syndrome, the epilepsy syndrome for which felbamate may be the most efficacious. ${ }^{10,11}$ Other established AEDs are commonly also used, including phenytoin, carbamazepine, and valproate. Many of these AEDs are associated with somnolence and difficulty concentrating. ${ }^{25}$ Valproate and carbamazepine have been associated with weight gain. Topiramate, like felbamate, has been associated with weight loss. ${ }^{26-28}$ Most of the AEDs have been associated with the risk of a fatal idiosyncratic reaction, although at lower frequency than occurs with felbamate. Phenytoin, carbamazepine, and phenobarbital may all be associated with serious rash, aplastic anemia, or fatal hepatotoxicity. ${ }^{29,30}$ Valproate is also associated with hepatotoxicity, with an overall incidence of $1 / 10,000$ to 49,000 , but the relative risk is different in certain 
subpopulations. The risk is lowest in patients older than 20 who receive valproate in monotherapy; the risk in the most vulnerable group, patients under age 2 receiving valproate in polytherapy, was $1 / 500$ to $800{ }^{31,32}$ Pancreatitis, at times fatal, has also been seen with valproate therapy. ${ }^{33-35}$ Lamotrigine may cause an allergic skin reaction that may be serious and require hospitalization. Younger age and concomitant valproic acid therapy increase the risk of this problem. In populations at risk, the incidence of serious rash may be $1 / 100 .{ }^{36}$ Fatal hypersensitivity syndromes have been reported as rare complications of lamotrigine use. ${ }^{37,38}$ Topiramate and gabapentin have not been associated with serious idiosyncratic reactions to date, although reports may emerge as more patients are exposed.

Epilepsy surgery is an alternative therapy in patients with uncontrolled seizures. In patients with partial seizures, focal resections are the procedure of choice. Such surgery carries a 1 to $2 \%$ risk of serious morbidity or mortality. Patients with Lennox-Gastaut syndrome who have tonic or atonic seizures, a group that responds well to felbamate therapy, may be candidates for a corpus callosotomy. This procedure is usually not curative, and is performed to reduce frequency and severity of seizures. Corpus callosotomy has been estimated to have a 5\% associated morbidity/mortality. ${ }^{39}$

\section{Conclusions.}

I. We found Class I evidence for benefits of felbamate:

A. Effective for:

1. Partial seizures in adults age 18 to 65 as adjunctive and monotherapy

2. Lennox-Gastaut syndrome as adjunctive therapy

II. We found Class III evidence for benefits of felbamate:

A. Effective for:

1. Primary generalized tonic-clonic convulsions

2. Absence seizures

3. Partial seizures in children

B. Comparative advantages over alternative therapies:

1. Less sedation

2. Weight loss

III. There was Class I evidence for the following risks of felbamate:

Side effects, including gastrointestinal disturbance, headache, anorexia, insomnia, dizziness, diplopia, ataxia, and rash.

IV. Evidence for serious risks of felbamate was Class III.

1. Strong evidence for the following risks were identified:

a. Aplastic anemia

b. Hepatic failure

c. Serious rash, including Stevens-Johnson and toxic epidermal necrolysis

Recommendations. We recognize the potential serious side effects that may exceed those of primary AEDs; however, felbamate can be an effective AED and has important advantages if used in certain patient populations.

We make the following recommendations as an advisory:

A. Patients for whom risk/benefit ratio supports use because there is Class I evidence for benefit.

1. Lennox-Gastaut patients over age 4 unresponsive to primary AEDs

2. Intractable partial seizures in patients over 18 years of age who have failed standard AEDs at therapeutic levels (monotherapy: data indicate a better risk/benefit ratio for felbamate used as monotherapy)

3. Patients on felbamate more than 18 months

B. Patients for whom the current risk/benefit assessment does not support the use of felbamate:

1. New onset epilepsy in adults or children

2. Patients who have experienced significant prior hematologic adverse events

3. Patients in whom follow-up and compliance will not allow careful monitoring

4. Patients unable to discuss risks/benefits (i.e., with mental retardation, developmental disability) and for whom no parent or legal guardian is available to provide consent

C. Patients in whom risk/benefit ratio is unclear and based on case reports and expert opinion (Class III) only, but under certain circumstances depending on the nature and severity of the patient's seizure disorder, felbamate use may be appropriate:

1. Children with intractable partial epilepsy 
2. Other generalized epilepsies unresponsive to primary agents

3. Patients who experience unacceptable sedative or cognitive side effects with traditional AEDs

4. Lennox-Gastaut syndrome under age 4 unresponsive to other AED

\section{Risk management.}

1. As therapy continues, risk/benefit ratio should be constantly assessed.

2. Patients should be educated as to early signs of potentially serious hepatic and hematopoetic side effects. These signs are: easy bruising, prolonged excessive bleeding, change in skin color, fatigue, fever, change in stool color, change in the color of the whites of the eye.

3. Laboratory monitoring has not been proved efficacious, but the manufacturer (Carter-Wallace), in conjunction with the FDA, suggests liver function tests at baseline and every 1 to 2 weeks for the first year of therapy, and also notes that complete blood count may identify hematologic changes before symptoms occur. There is no evidence that such monitoring will prevent adverse outcomes. After the first year, the risk of aplastic anemia drops and the need for ongoing laboratory screening is even less clear.

4. Even though individual clinical practice may vary, patients should be advised of the manufacturer's recommendations.

Future research. Future research should be performed to determine the following information:

1. Potential risk factors that may be associated with the development of serious adverse events with felbamate use.

2. Potential for diagnostic testing that would predict susceptibility to serious adverse events.

We recommend that physicians prescribing felbamate register their patients in the Felbatol Registry so that these goals may be accomplished. The registry can be contacted at: Felbatol Registry Program, Wallace Laboratories Data Management Services, PO Box 1001, Half-Acre Road, Cranbury, NJ 08512-0181.

Disclaimer. This statement is provided as an educational service of the American Academy of Neurology (AAN). It is based on an assessment of current scientific and clinical information. It is not intended to include all possible proper methods of care for a particular neurologic problem or all legitimate criteria for choosing to use a specific procedure. Neither is it intended to exclude any reasonable alternative methodologies. The AAN recognizes that specific patient care decisions are the prerogative of the patient and the physician caring for the patient, based on all of the circumstances involved.

\section{Acknowledgments}

The AAN Quality Standards Subcommittee thanks Jacqueline French, MD, for her service to the Academy as the lead author and facilitator of this practice advisory project, and the members of the expert panel who provided their time and expertise to the development of this document. They also thank the numerous individuals, AAN Sections, and organizations that reviewed drafts of the document, including the American Epilepsy Society, the Epilepsy Foundation of America, and the Child Neurology Society.

The authors thank Joanne Okagaki, who contributed her administrative skills and expertise to this project. They also thank Wendy Edlund, who provided invaluable assistance. Finally, they acknowledge the input from the American Epilepsy Society, and in particular Ilo Leppik, MD.

\section{Appendix 1}

\section{Quality of evidence ratings}

Class I: Well-designed, prospective, blinded, controlled studies.

Class II: Well-designed clinical studies, such as case control, cohort studies, etc.

Class III: Evidence provided by expert opinion, nonrandomized historic controls, or case reports of one or more.

\section{Definitions}

Standard: A principle for patient management that reflects a high degree of clinical certainty (usually this requires Class I evidence that directly addresses the clinical question, or overwhelming Class II evidence when circumstances preclude randomized clinical trials). 
Guideline: A recommendation for patient management that reflects moderate clinical certainty (usually this requires Class II evidence or a strong consensus of Class III evidence).

Practice option: A strategy for patient management for which the clinical utility is uncertain (inconclusive or conflicting evidence or opinion).

Practice Advisory: A practice recommendation for emerging and/or newly approved therapies or technologies based on evidence from at least one Class I study. The evidence may demonstrate only a modest statistical effect or limited (partial) clinical response, or significant cost-benefit questions may exist. Substantial (or potential) disagreement among practitioners or between payers and practitioners may exist.

\author{
Appendix 2 \\ American Academy of Neurology Quality Standards Subcommittee Members: Gary Franklin, MD - Co-Chair; \\ Catherine Zahn, MD —Co-Chair; Milton Alter, MD, PhD; Stephen Ashwal, MD; John Calverley, MD; Richard \\ Dubinsky, MD; Jacqueline French, MD; Michael Greenberg, MD; Gary Gronseth, MD; Deborah Hirtz, MD; Robert \\ Miller, MD; James Stevens, MD.
}

\title{
Disclosure
}

Drs. French and Faught have received research support from Carter-Wallace Pharmaceuticals. Drs French, Faught, and Smith are past members of a speakers' bureau supported by Carter-Wallace. Dr. Faught has been a consultant for Carter-Wallace.

\section{References}

1. Leppik IE. Felbamate. Epilepsia 1995;36(suppl 2):S66-S72.

2. Cruzan S. Suspension of Felbatol use urged. Washington, DC: Press office, Food and Drug Administration, United States Department of Health and Human Services; August 1, 1994.

3. Costin JC. Recommendations for monitoring liver function tests in patients being treated with Felbatol (felbamate). Cranbury, NJ: Wallace Laboratories, September 1994.

4. Theodore WH, Raubertas R, Porter RJ, et al. Felbamate: a clinical trial for complex partial seizures. Epilepsia 1991;32:392-397.

5. Leppik IE, Dreifuss FE, Pledger GW, et al. Felbamate for partial seizures: results of a controlled clinical trial. Neurology 1991;41:1785-1789.

6. Bourgeois B, Leppik IE, Sackellares JC, et al. Felbamate: a double-blind controlled trial in patients undergoing presurgical evaluation of partial seizures. Neurology 1993;43:693-696.

7. Devinsky O, Faught RE, Wilder BJ, et al. Efficacy of felbamate monotherapy in patients undergoing presurgical evaluation of partial seizures. Epilepsy Res 1995;20:241-246.

8. Faught E, Sachdeo RC, Remler MP, et al. Felbamate monotherapy for partial-onset seizures: an active control trial. Neurology 1993;43:688-692.

9. Sachdeo R, Kramer LD, Rosenberg A, Sachdeo S. Felbamate monotherapy: controlled trial in patients with partial onset seizures. Ann Neurol 1992;32:386-392.

10. Felbamate Study Group in the Lennox-Gastaut Syndrome. Efficacy of felbamate in childhood epileptic encephalopathy (Lennox-Gastaut syndrome). N Engl J Med 1993;328:29-33.

11. Motte J, Trevathan E, Ardvisson JFV, et al., and the Lamictal Lennox-Gastaut study group. Lamotrigine for generalized seizures associated with the Lennox-Gastaut syndrome. N Engl J Med 1997;337:1807-1812.

12. Sachdeo RC, Murphy JV, Kamin M. Felbamate in juvenile myoclonic epilepsy. Epilepsia 1992;33(suppl 3):118. Abstract.

13. Kuzniecky R, Thompson G, Faught E, Kramer L. Felbamate add-on therapy in intractable atypical absence. Epilepsia 1991;32(suppl 3):10. Abstract.

14. Devinsky O, Kothari M, Rubin R, Mercandetti R, Luciano D. Felbamate for absence seizures. Epilepsia 1992;33(suppl 3):84. Abstract.

15. Leroy RF, Castain T. Pilot study of felbamate in adult medically refractory primary generalized seizure patients. Epilepsia 1991;32(suppl 3):13. Abstract.

16. Sachdeo RC, Wagner ML. Felbamate in generalized tonic-clonic seizures. Epilepsia 1991;32(suppl 3):54. Abstract.

17. Carmant L, Holmes GL, Sawyer S, Rifai N, Anderson J, Mikati MA. Efficacy of felbamate in therapy for partial epilepsy in children. J Pediatr 1994;125:481-486. 
18. Travaglini MT, Morrison RC, Ackerman BH, Haith LR Jr, Patton ML. Toxic epidermal necrolysis after initiation of felbamate therapy. Pharmacotherapy 1995;15:260-264.

19. Pellock JM, Brodie MJ. Felbamate: 1997 update. Epilepsia 1997;38:1261-1269.

20. Kaufman DW, Kelly JP, Anderson T, Harmon DC, Shapiro S. Evaluation of case reports of aplastic anemia among patients treated with felbamate. Epilepsia 1997;38:1265-1269.

21. Hauser WA, Annegers JF, Elveback LR. Mortality in patients with epilepsy. Epilepsia 1980;21:339-412.

22. Guberman A. Seizure-related injuries and death in adult epilepsy. Can J Neurol Sci 1990;17:256. Abstract.

23. Vickrey BG, Hays RD, Engel J Jr, et al. Outcome assessment for epilepsy surgery: the impact of measuring health-related quality of life. Ann Neurol 1995;37:158-177.

24. Farrell K. Symptomatic generalized epilepsy and the Lennox-Gastaut syndrome. In: Wyllie E, ed. The treatment of epilepsy, principles and practice, 2nd ed. Baltimore: Williams \& Wilkins, 1996:530-539.

25. Plaa GL, Willmore JL. General principles: toxicology. In: Levy RH, Mattson RH, Meldrum BS, eds. Antiepileptic drugs, 4th ed. New York: Raven Press, 1995:51-60.

26. Ben-Menachem E. Topiramate. In: Antiepileptic drugs, fourth edition. Levy RH, Mattson RH, Meldrum BS, eds. Antiepileptic drugs, 4th ed. New York: Raven Press, 1995:1063-1070.

27. Messenheimer J, Ramsay RE, Willmore LJ, et al. Lamotrigine therapy for partial seizures: a multicenter, placebo-controlled, double-blind, crossover trial. Epilepsia 1994;35:113-121.

28. Mattson RH, Cramer JA, Collins JF, et al. Comparison of carbamazepine, phenobarbital, phenytoin, and primidone in partial and secondary generalized tonic-clonic seizures. N Engl J Med 1985;313:145-151.

29. Pellock JM. Carbamazepine side effects in children and adults. Epilepsia 1987;28(suppl 3):S64-S70.

30. Hart RB, Easton JD. Carbamazepine and hematologic monitoring. Ann Neurol 1982;11:309-312.

31. Dreifuss FE, Langer DH, Moline KA, Maxwell JE. Valproic acid hepatic fatalities II: US experience since 1984. Neurology 1988;33:201-207.

32. Bryant AE, Dreifuss FE. Valproic acid hepatic fatalities: US experience since 1986. Neurology 1996;46:465468.

33. Camfield PR. Pancreatitis due to valproic acid. Lancet 1979;1:1198-1199.

34. Coulter DL, Allen RJ. Pancreatitis associated with valproic acid therapy for epilepsy. Ann Neurol 1980;7:92. Letter.

35. Wyllie E, Wyllie R, Cruse RP, Erenberg G, Rothner AD. Pancreatitis associated with valproic acid therapy. Am J Dis Child 1984;138:912-914.

36. Yuen AWC. Safety issues. In: Richens A, ed. Clinical update on lamotrigine: a novel antiepileptic agent. Tunbridge Wells: Wells Medical Ltd., 1992:69-75.

37. Makin AJ, Fitt S, Williams R. Fulminant hepatic failure induced by lamotrigine. BMJ 1995;311:292. Letter.

38. Schaub JEM, Williamson PJ, Barnes EW, Trewby PN. Multisystem adverse reaction to lamotrigine. Lancet 1994;344:481. Letter.

39. Wyler AR. Corpus callosotomy. In: Wyllie E, ed. The treatment of epilepsy, principles and practice, 2 nd ed. Baltimore: Williams \& Wilkins, 1996:1097-1102.

Approved by the AAN Quality Standards Subcommittee October 17, 1998. Approved by the Practice Committee January 23, 1999. Approved by the Executive Board of the AAN February 27, 1999. Published in Neurology 1999;52:1540-1545. 


\section{Neurology}

Practice advisory: The use of felbamate in the treatment of patients with intractable epilepsy: Report of the Quality Standards Subcommittee of the American Academy of Neurology and the American Epilepsy Society

J. French, M. Smith, E. Faught, et al.

Neurology 1999;52;1540

DOI 10.1212/WNL.52.8.1540

\section{This information is current as of May 1, 1999}

\section{Updated Information \& Services}

References

Citations

Permissions \& Licensing

Reprints including high resolution figures, can be found at: http://n.neurology.org/content/52/8/1540.full

This article cites 32 articles, 5 of which you can access for free at: http://n.neurology.org/content/52/8/1540.full\#ref-list-1

This article has been cited by 6 HighWire-hosted articles: http://n.neurology.org/content/52/8/1540.full\#\#otherarticles

Information about reproducing this article in parts (figures,tables) or in its entirety can be found online at:

http://www.neurology.org/about/about_the_journal\#permissions

Information about ordering reprints can be found online:

http://n.neurology.org/subscribers/advertise

Neurology ${ }^{\circledR}$ is the official journal of the American Academy of Neurology. Published continuously since 1951, it is now a weekly with 48 issues per year. Copyright . All rights reserved. Print ISSN: 0028-3878. Online ISSN: $1526-632 X$.

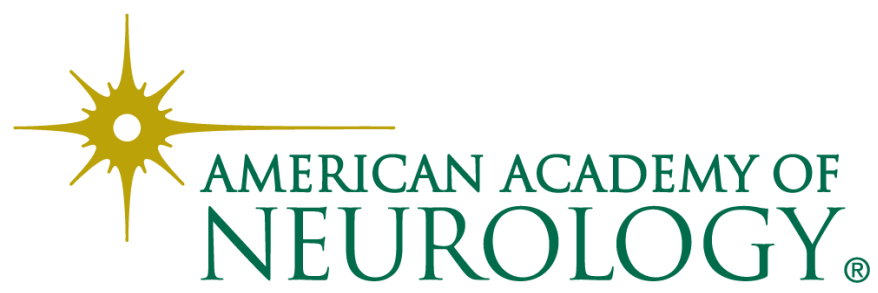

